\title{
Control Beliefs among People with Dementia: A Systematic Review
}

\author{
Ingeborg Halse ${ }^{a, b, c}$ Guro Hanevold Bjørkløf ${ }^{a}$ Knut Engedal $^{a, b}$ Geir Selbæk ${ }^{a, b, c}$ \\ Maria Lage Barca ${ }^{a, b}$ \\ aNorwegian National Advisory Unit on Ageing and Health, Vestfold Hospital Trust, Tønsberg, Norway; ${ }^{b}$ Department of \\ Geriatric Medicine, Oslo University Hospital-Ullevål, Oslo, Norway; ${ }^{\circ}$ Faculty of Medicine, University of Oslo, Oslo, Norway
}

\author{
Keywords \\ Dementia · Control beliefs · Self-efficacy · Coping · \\ Psychosocial interventions
}

\begin{abstract}
Introduction: Dementia diseases are still incurable, and in order to assist in living well with the disease, researchers are increasing their attention to the value of control beliefs. Control beliefs are associated with coping and psychological well-being; however, knowledge on how they relate to wellbeing outcomes in people with dementia is limited. This review aimed to synthesize knowledge about control beliefs in this group to guide future interventions and research. Method: A systematic search of 6 databases (MEDLINE, CINAHL, PsychINFO, AgeLine, Embase, and the Cochrane Library) with broad search terms related to dementia, control, and coping was conducted. Studies that investigated people with a confirmed dementia diagnosis and that used a questionnaire to measure control beliefs quantitatively were included. Results: Eighteen studies were identified, examining self-efficacy, personal control/mastery, or locus of control. The studies varied in aim and design, with fair to good methodological quality. However, 10 studies included $<50$ par-
\end{abstract}

karger@karger.com www.karger.com/dem

Karger $\stackrel{\text { ' }}{5}$
(C) 2021 The Author(s)

Published by S. Karger AG, Basel

This is an Open Access article licensed under the Creative Commons Attribution-NonCommercial-4.0 International License (CC BY-NC) (http://www.karger.com/Services/OpenAccessLicense), applicable to the online version of the article only. Usage and distribution for commercial purposes requires written permission. ticipants with dementia, leaving findings unreliable due to low power. Participants with dementia in the mild to moderate stages were included, with average age in the seventies. Except for one validation study, the control belief questionnaires had not been validated for people with dementia. Conclusion: There is a lack of knowledge about control beliefs among people with dementia, due to few and low-powered studies. Although we cannot conclude regarding control beliefs, our findings support the feasibility of quantitative research on control beliefs among people with dementia and we recommend that they be included in this type of research.

\footnotetext{
(c) 2021 The Author(s)

Published by S. Karger AG, Basel
}

\section{Introduction}

No cure or treatment that can delay the progression of any dementia disorders are yet available, and due to an increase of older adults worldwide, the number of people with dementia will rise substantially in the years to come [1]. Over time, dementia leads to decreased ability to function cognitively, socially, and independently in everyday life. A growing interest regarding how to live and 
cope with dementia is emerging [2]. Knowledge about how people cope with dementia has value for implementing interventions that target adaptive coping strategies for activities of daily living as well as behavioral and psychological symptoms due to the disease.

Control beliefs has been an area of research for more than half a century in social, personality, and clinical psychology. Experiencing a sense of control has repeatedly been shown to be beneficial when coping with a variety of health problems $[3,4]$. Many control constructs have been developed [5], and the most prominent are locus of control, learned helplessness, mastery, and self-efficacy. Although defined as distinct constructs, each definition attempts to explain how a person views his/her abilities, effort, or expectations of realizing an outcome. Indeed, several constructs and definitions have been proposed as indicators of the same underlying personality construct [6].

Studies have shown control beliefs to be beneficial for coping $[7,8]$. In health research, for example, perception of control has been found to affect one's ability to engage in positive health behaviors and adjust to a demanding situation [9]. In the 1970s, Langer and Rodin [10] demonstrated how a perception of control can positively impact upon well-being among nursing-home residents. In their intervention study, residents who were given more responsibilities in daily decision-making reported to be happier and appeared more active than that of a comparison group given the same activities but with a fixed time schedule. A positive difference was measurable even 18 months after the intervention. In addition, the study reported that the persons in the intervention group tended to live longer than those in the control group [11]. This study bridged the research on control among older people and control in health-related situations and helped shape subsequent gerontological research [8].

Control beliefs among older adults have been associated with the same tendencies as found among younger adults; less perceived control negatively affects well-being, and more perceived control leads to positive outcomes and overall successful aging $[4,8]$. In addition, among healthy older people, more perceived control has been associated with greater use of effective strategies to improve memory and to maintain cognitive functioning $[4,7,12]$. According to Bandura [13], a person will invest more effort in a task when the outcome is believed to be attainable. As control beliefs are important to both mental well-being and cognition, they are likely important elements of psychosocial interventions for people with dementia. Knowledge about how con- trol beliefs function among people with dementia could assist informal caregivers and health-care personnel in helping this group to cope with their progressive disease.

\section{Research Aim}

The aim of the present review was to synthesize knowledge on control beliefs among people with dementia by performing a systematic search of relevant quantitative research studies. By doing so, we wished to illuminate the present knowledge base and help guide future research on this topic.

\section{Methods}

\section{Selection of Eligible Studies}

A systematic, computerized search of quantitative research literature was conducted in the MEDLINE, CINAHL, PsychINFO, AgeLine, Embase, and the Cochrane Library databases. The search was conducted by a research librarian at 3 time points, April 2019, October 2019, and January 2021. The second and third searches were restricted to articles published after January 2019.

The search strategy included Medical Subject Headings (MeSH), keywords, and text words for the following constructs: dementia, control, and coping. Perceived control can be viewed as an aspect of coping, and it is possible that some researchers have examined coping with the use of a control instrument; hence, coping was included in order to increase the likelihood of incorporating all relevant research. Control beliefs have been defined in numerous ways [5]; thus, we performed a search with a variety of search terms in order to encompass relevant studies (see Appendix 1 for an overview of dementia search terms and Appendix 2 for control and coping search terms).

The inclusion criteria in this review were research conducted by including persons with a confirmed dementia diagnosis, who had responded to a control belief instrument. Additionally, the research had to be original and peer-reviewed, have a quantitative design, and published after the year 2000. Reviews, protocols, conference abstracts, posters, or theoretical research were excluded as were articles in a language other than English. We also excluded articles that studied persons with dementia and mild cognitive impairment $(\mathrm{MCI})$ as a single group, since we wished to have a clear focus on dementia.

The selection of relevant articles was performed in dyads to reduce the risk of oversights. One author was a member of every dyad throughout the selection process to ensure consistency. After an initial elimination of duplicates by EndNote, the selection procedure was performed as follows: First, all titles were divided into 3 parts and delegated at random to the 3 pairs (of the co-authors). Article titles that clearly did not meet the inclusion criteria were discarded. Disagreements within the dyads were resolved by consulting the other co-authors. The procedure was repeated when delegating and reading the abstracts, skimming the full articles, and, finally, when comprehensibly reading the remaining articles. Last, a search for additional articles was conducted by examining the reference lists of all included articles. 


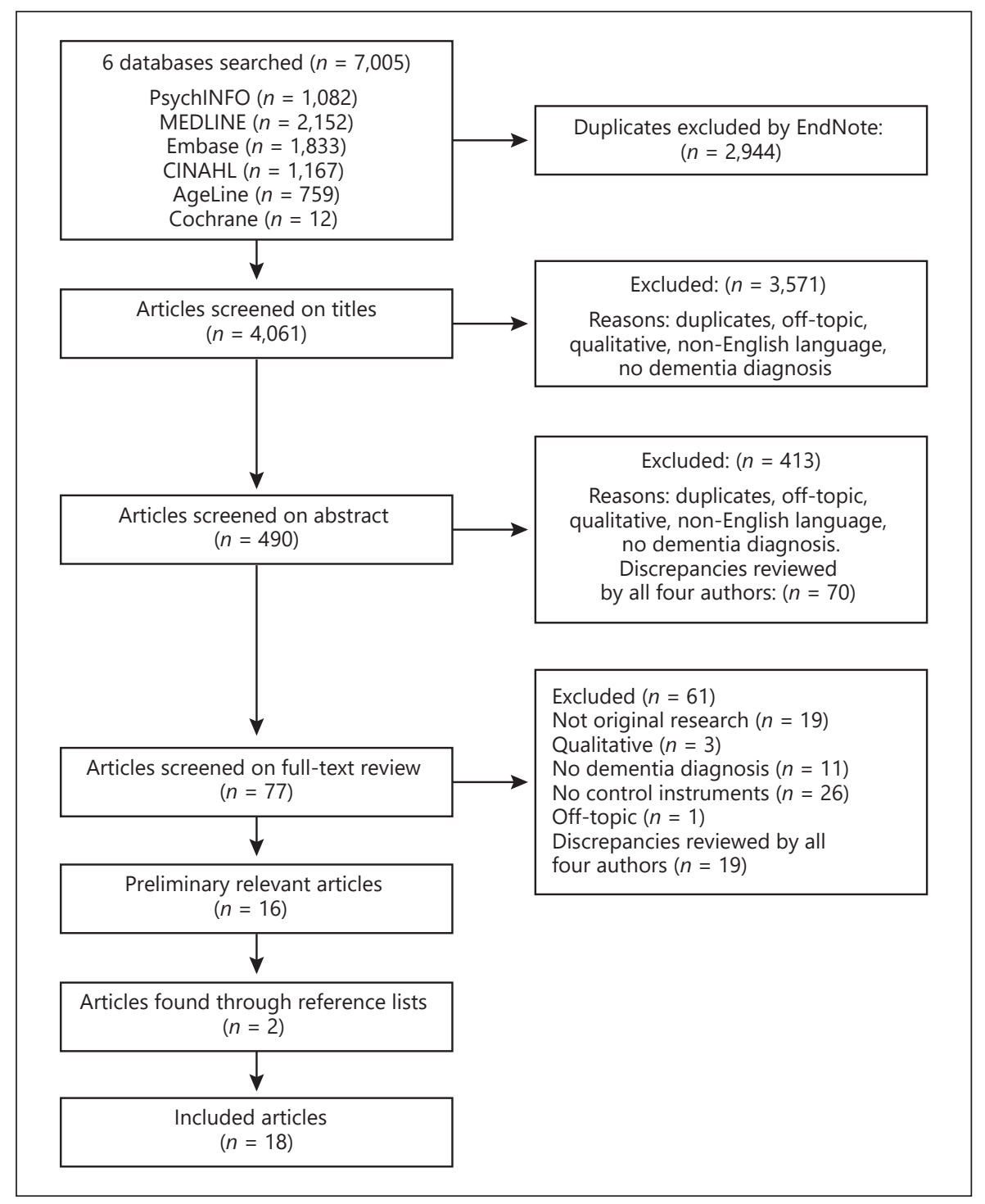

Fig. 1. Overview of the review process.

Quality Assessment

A quality assessment of each article was performed using the critical appraisal tool developed by Hawker et al. [14]. This tool is applicable to all study designs and comprises 9 areas for review: Abstract and Title; Introduction and Aims; Method and Data; Sampling; Data Analysis; Ethics and Bias; Results; Transferability and Generalizability; and Implications and Usefulness. Each area is given a score between 1 and 4 based on a set of guiding criteria; the minimum sum score is 9 and the maximum is 36 . A higher total score indicates better quality. Two authors scored the articles separately, and minor disagreements of one point were averaged. No articles were excluded based on their quality assessment. The appraisal tool by Hawker et al. [14] allows for an assessment that focuses on the quality of each research article regardless of study design, meaning that a cross-sectional study can receive a score equal to a randomized controlled trial.

Control Beliefs among People with Dementia

\section{Results}

The 3 electronic searches yielded a total of 7,005 articles (final search performed in February 2021). EndNote was used to eliminate duplicates, resulting in 4,061 articles to be assessed for eligibility by the authors. After elimination first by a review of titles, then by abstracts followed by full-text readings, 16 articles remained. Two additional articles were found through examination of reference lists; thus, 18 articles were included in this review. Figure 1 shows the review process.

\section{Methodological Quality of the Studies}

As shown in Table 1, the studies had good methodological quality, with 12 studies receiving a score above 
Table 1. Quality assessment of studies

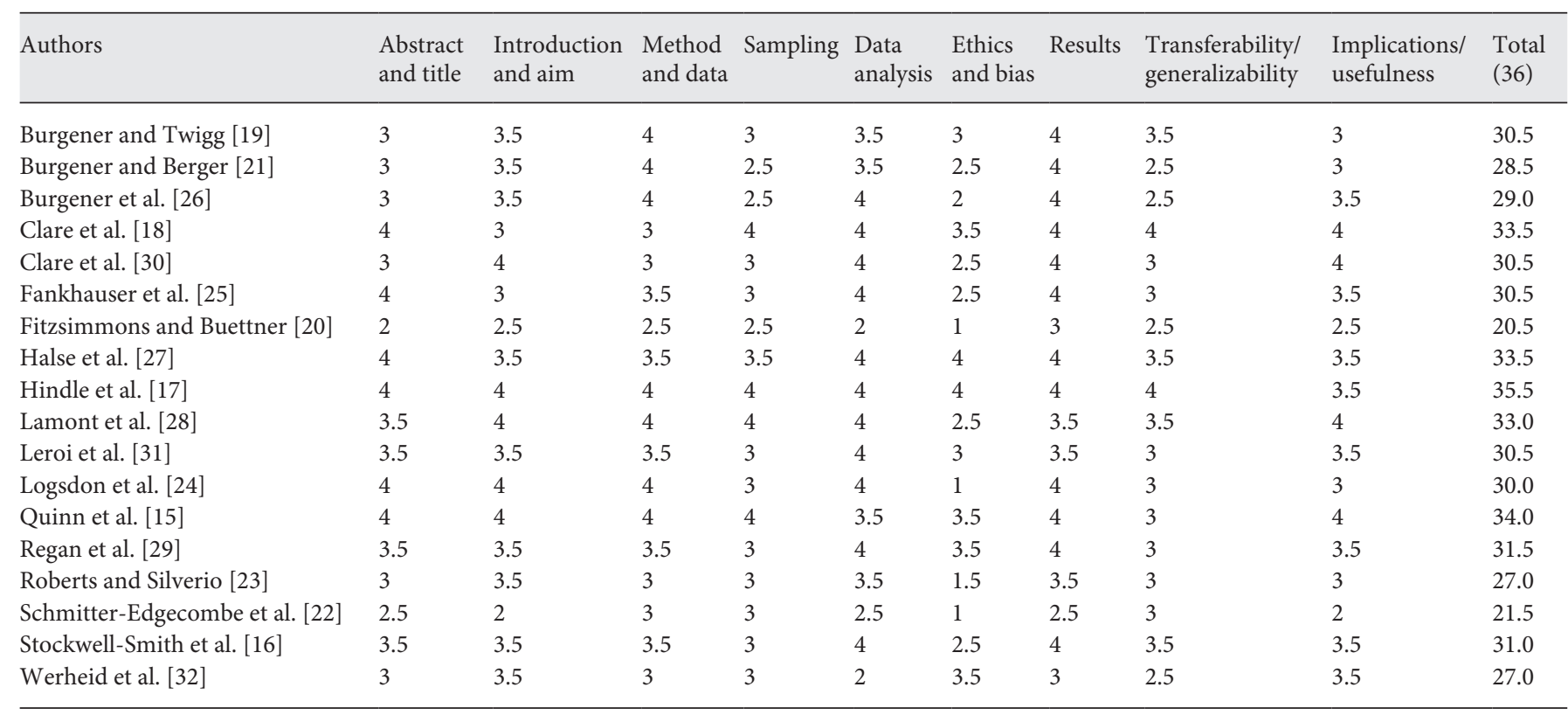

Assessment done using the appraisal tool by Hawker et al. [14]. 1, very poor; 2, poor; 3, fair; 4, good.

30, and no studies below 20. The studies were, in general, well-justified with good methodological considerations, clear results and discussion sections, and appropriate conclusions regarding implications and usefulness. However, only one study used a control belief questionnaire validated for people with dementia and 10 included $<50$ participants with dementia.

\section{Study Designs of the Articles}

Of the 18 included articles, 11 were intervention studies, of which 7 were pilot studies. The remaining 7 articles were observational studies, of which 2 focused on scale psychometrics. Only 2 intervention studies examined control belief as the primary outcome $[15,16]$ and another 2 as part of the secondary outcomes $[17,18]$. The remaining intervention and observational studies included control beliefs as exploratory outcome measures or as dependent measures without further specifications [1932].

Heterogeneity in terms of aim, study design, sample size and outcome measures deemed a non-statistical synthesis of the results appropriate. Table 2 shows an overview of the study details.

\section{Study Settings}

The participants' home was the research setting in 9 studies [16-19, 21, 23, 28, 30,31], while 3 were performed in recreational facilities, adult day care or senior centers, or in an assisted living facility [20,24,29]. One study was performed in a memory clinic [15], one allowed participants to choose between home or memory clinic [26], and another collected data at participants' home, day care, or memory clinic [27]. Finally, 3 studies did not specify research setting $[22,25,32]$.

\section{Participants}

Although the age range of the participants with dementia varied from 52 to 96 years, mean age in all studies was in the 70s. Four studies had an age specification as part of their inclusion criteria, with a minimum age varying between 55 and 65 years [16, 17, 25, 27]. See Table 3 for an overview of demographics regarding participants with dementia. Demographics of participating caregivers or comparison groups are not presented in this review.

\section{Dementia Diagnosis}

All studies in this review included participants with a confirmed dementia diagnosis; however, only 10 reported which diagnostic criteria had been used [15-18, 22, 25 , $27,28,30,32]$. Five studies $[15,18,27,28,30]$ diagnosed dementia according to the International Statistical Classification of Diseases and Related Health Problems, 10th revision (ICD-10) criteria [33], one study [32] used the Diagnostic and Statistical Manual of Mental Disorders, 


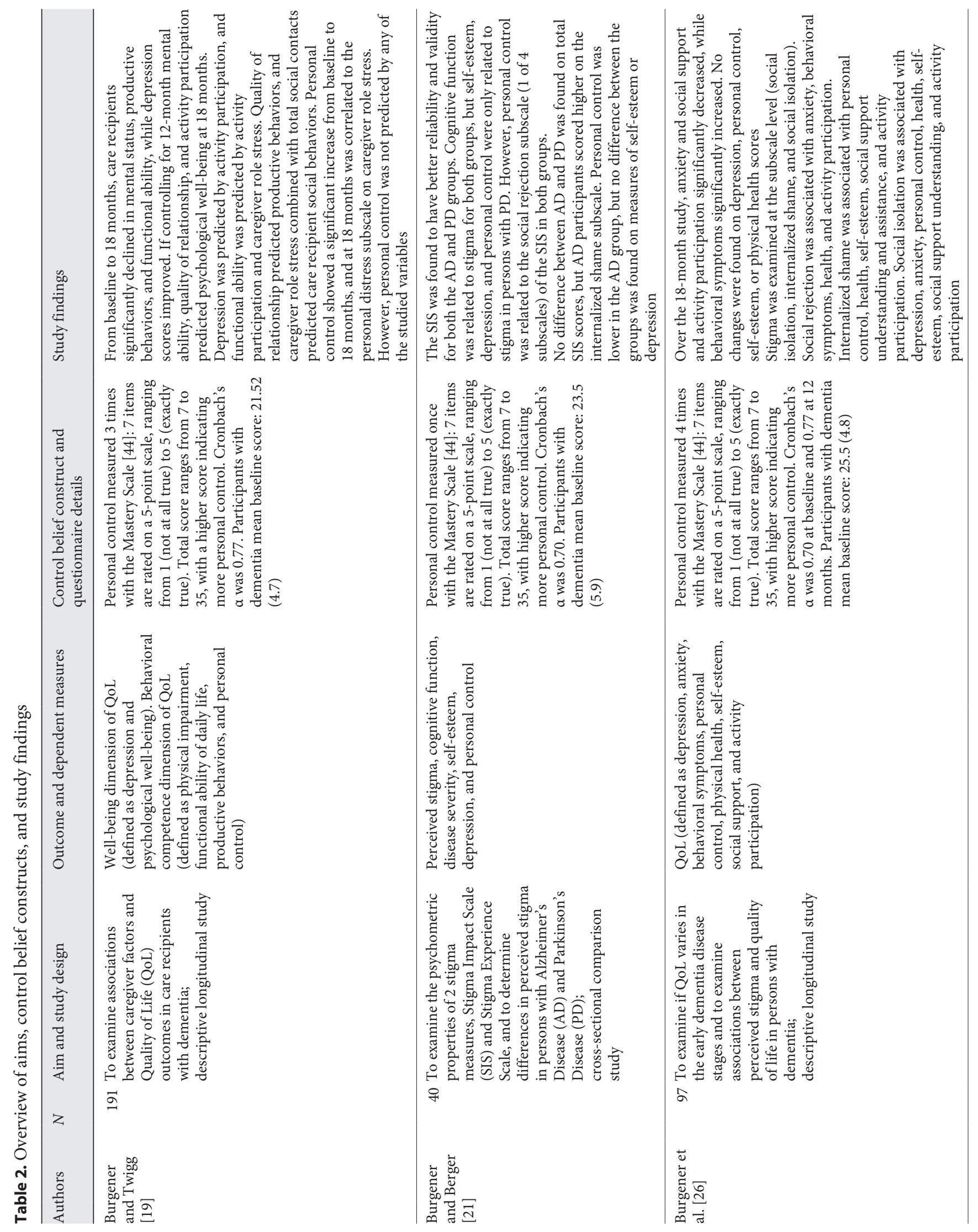




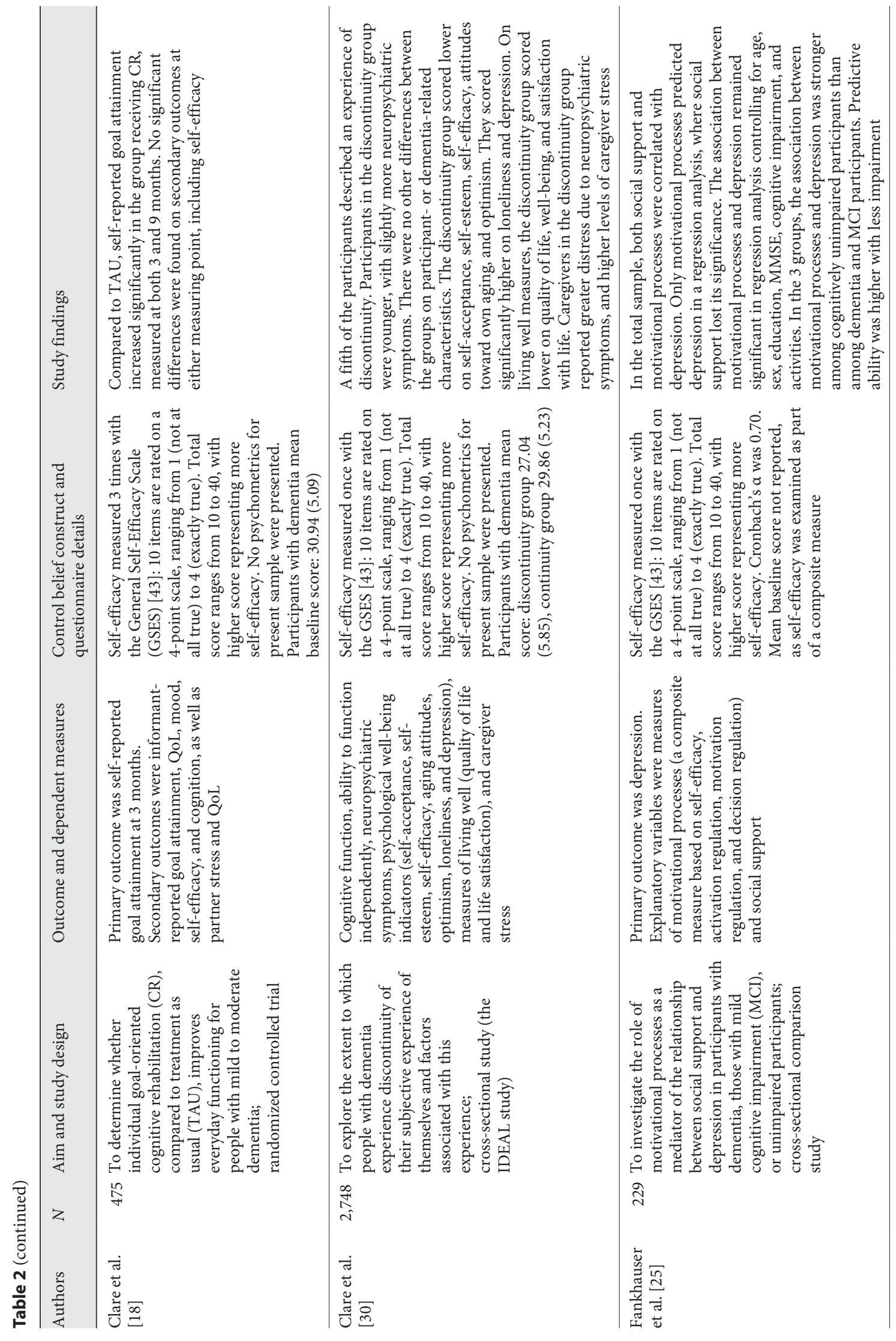




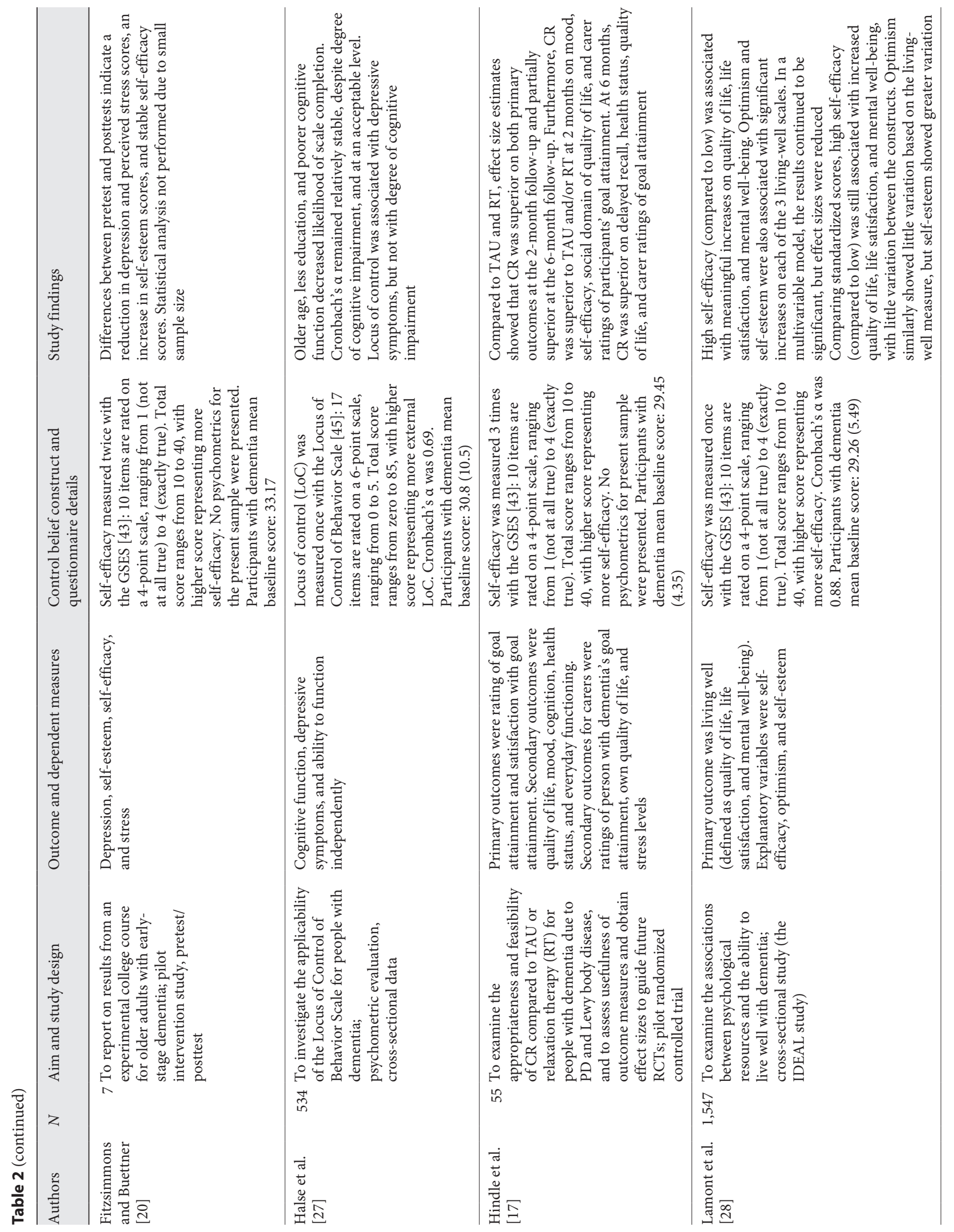




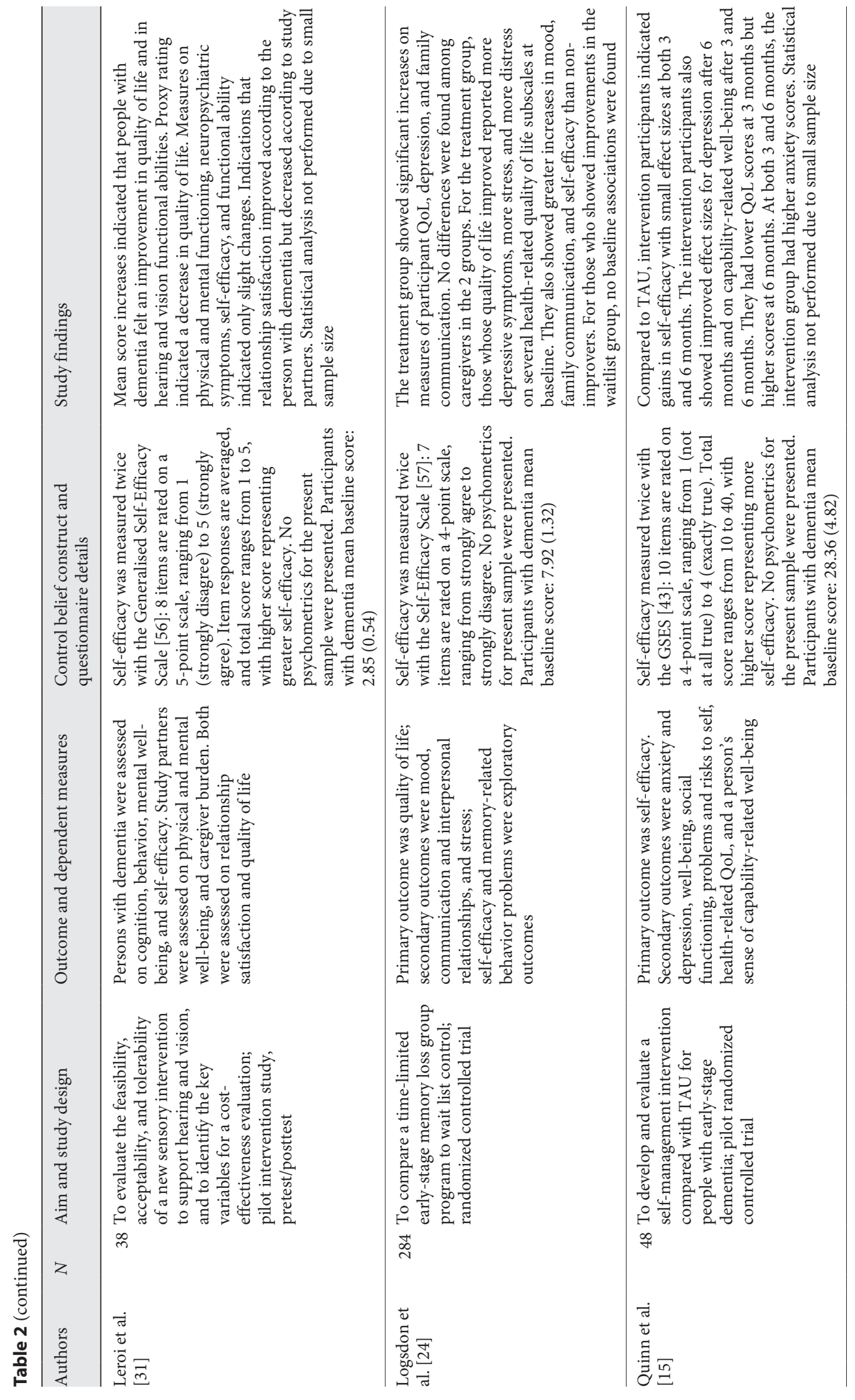




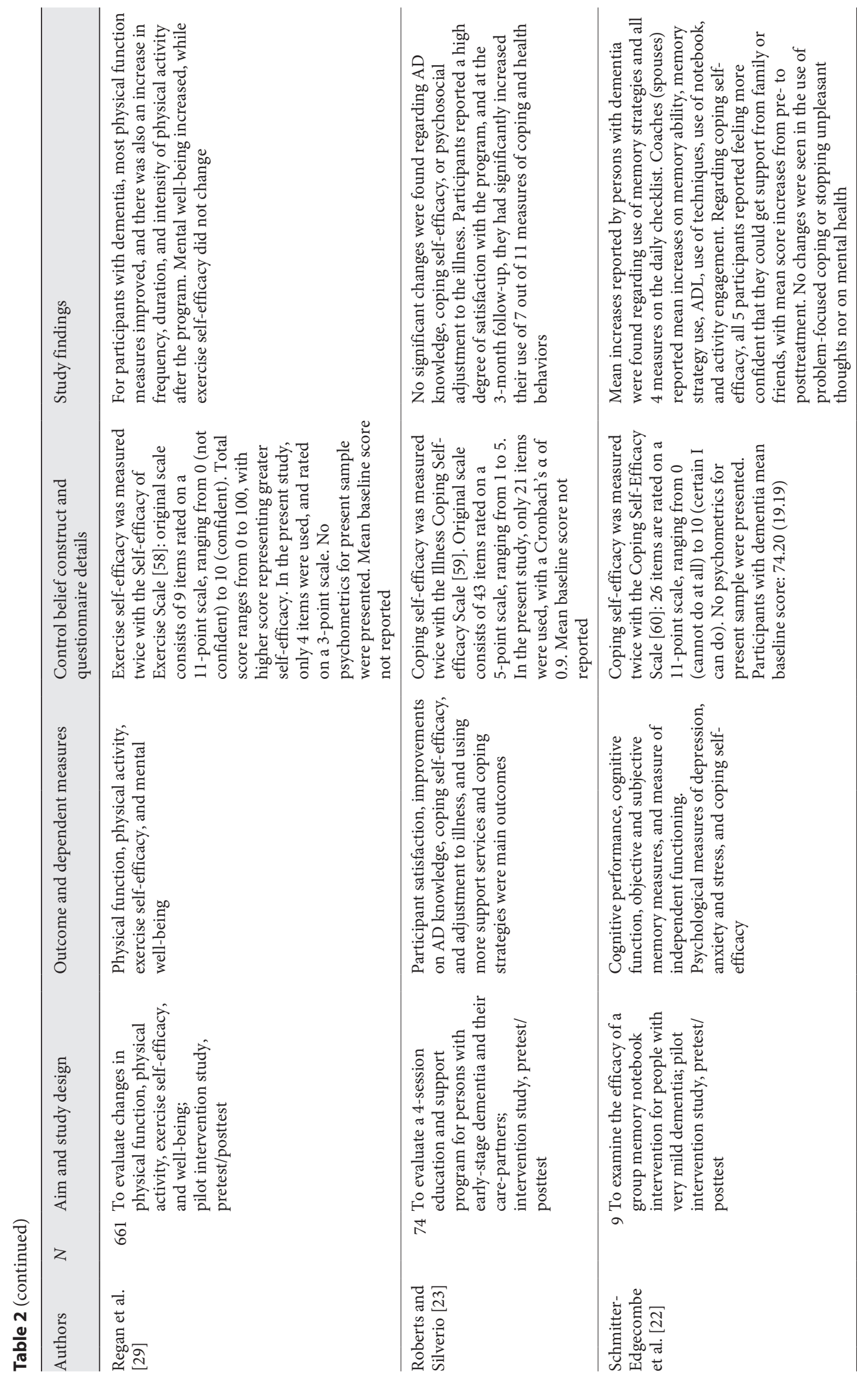




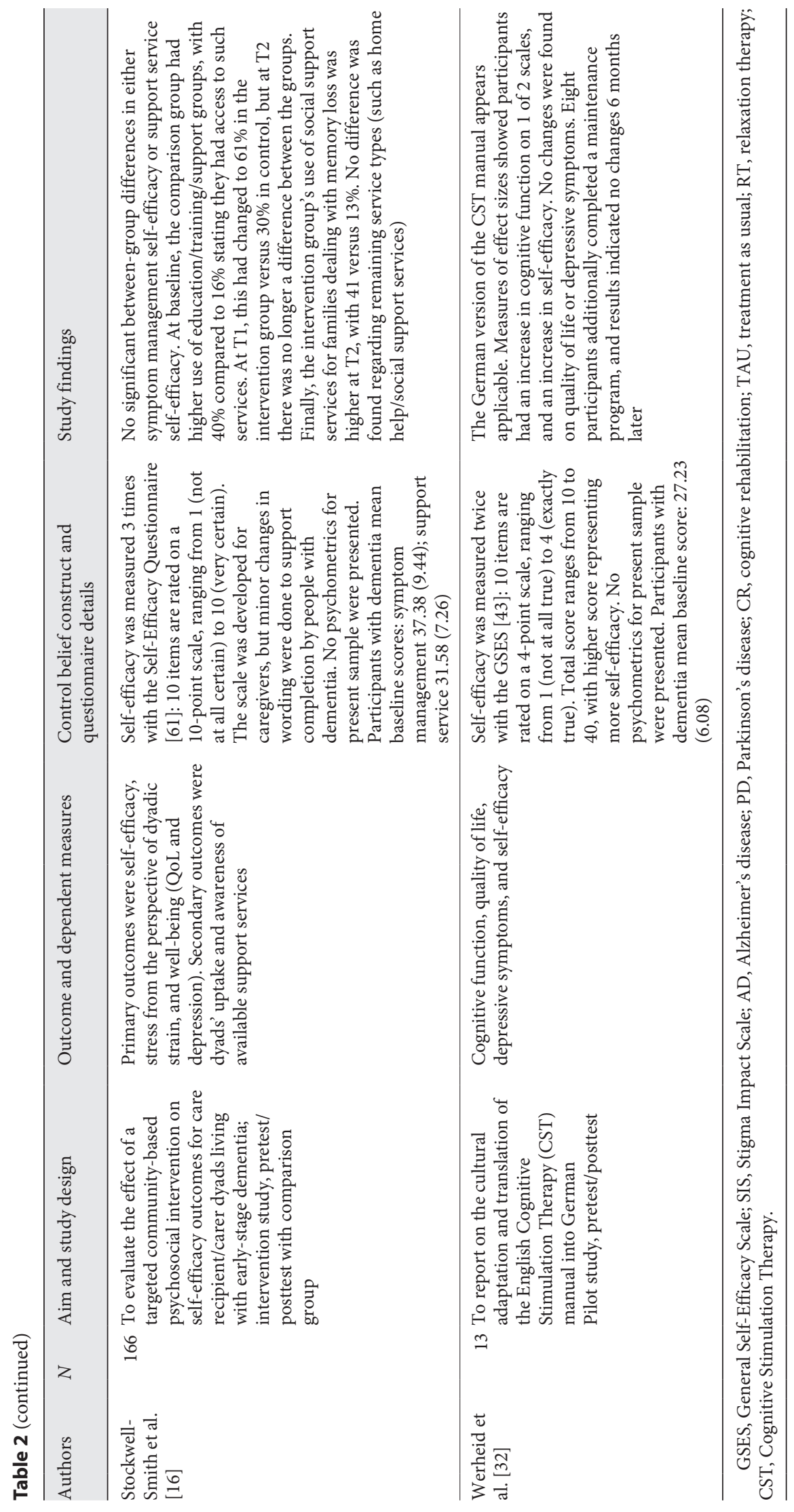




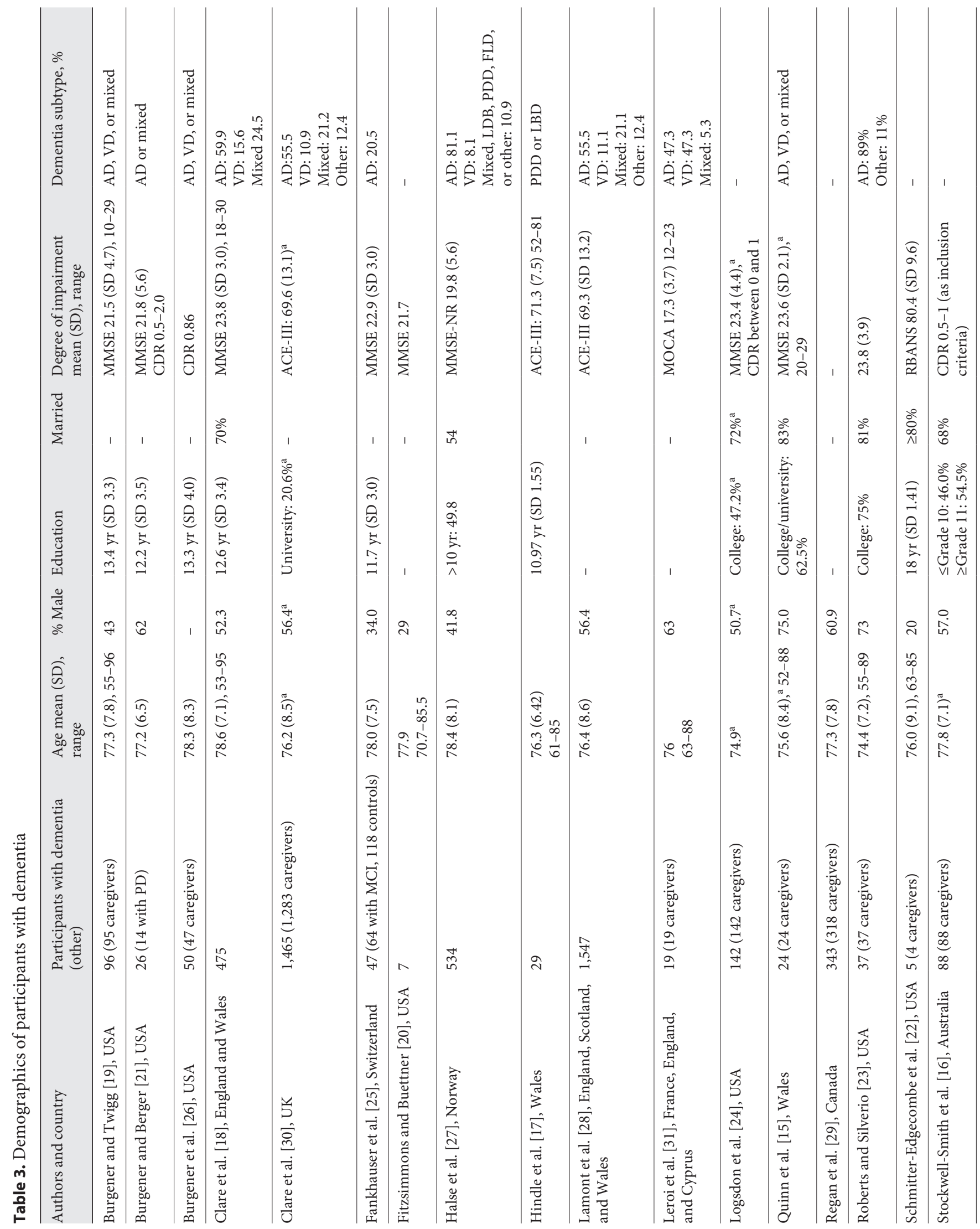




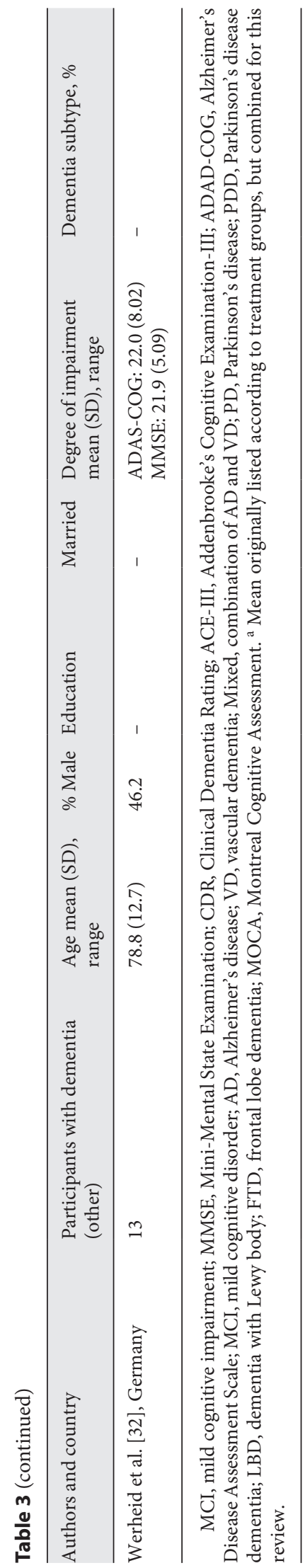

4th edition (DSM-IV) criteria [34], and 2 studies [16, 22] based the dementia diagnosis on the Clinical Dementia Rating Scale (CDR) $[35,41]$. Two studies based the dementia diagnosis on consensus criteria. One [25] used the criteria established by the National Institute of Neurological and Communicative Disorders and Stroke/Alzheimer's Disease and Related Disorders Association [36], and the other study used the criteria established by the Movement Disorder Society [37, 38] and by the Dementia with Lewy Bodies consortium [39].

Where reported, the percentage of participants diagnosed as having Alzheimer's disease (AD) ranged from 47 to $89 \%[18,23,25,27,28,30,31]$. See Table 3 for overview of prevalence of diagnoses in individual studies. If specific dementia diagnoses were among the inclusion criteria, $\mathrm{AD}$, vascular dementia $(\mathrm{VD})$, or mixed $\mathrm{AD} / \mathrm{VD}$ were the most commonly used diagnoses $[15,18,19,21,25,26$, $28,31]$. One study only included participants with dementia due to Parkinson's disease (PD) or Lewy body disease [17]. The remaining studies either included all types of dementia $[23,27,30]$ or did not specify the etiological dementia diagnosis $[16,20,22,24,29,32]$.

\section{Dementia Severity}

Degree of dementia severity was an inclusion criterion in 11 studies, all of which recruited participants with mild to moderate dementia severity $[15,16,18,21-23,25,28$, 30-32]. A definition of mild to moderate severity was presented in 9 studies, using 8 different types of criteria. Mini-Mental State Examination (MMSE) score [40] was used in 4 studies, and mild to moderate dementia was defined as either $\geq 15[28,30]$ or $\geq 18$ [18], or $\geq 20$ [15]. The CDR $[35,41]$ was used in 3 studies, indicating either very mild dementia with a score of 0.5 [22], mild dementia with a score of 0.5-1.0 [16], or mild to middle stage dementia with a score of $0.5-2.0$ [21]. One study used a score of $\geq 12$ on the Montreal Cognitive Assessment (MOCA) scale [42] to indicate mild to moderate dementia [31], and the final study used the DSM-IV to define mild to moderate dementia [32]. A further 3 studies also had cognitive assessment requirements as part of their inclusion criteria, but without indicating their purpose $[17,24,26]$.

\section{Constructs of Control Beliefs}

Although many control constructs are described in the literature [5], self-efficacy [13] was most frequently applied in the included studies of this review. In all, 7 different scales measuring self-efficacy were used in 14 studies. Eleven studies measured self-efficacy at 2 or more time 
points [15-18, 20, 22-24, 29, 31, 32]. The General SelfEfficacy Scale (GSES) [43] was used in 8 studies and the remaining 6 self-efficacy scales [56-61] in one study each (see Table 2). The Mastery scale developed by Pearlin and Schooler [44] was used in 3 studies to examine personal control $[19,21,26]$. One study examined locus of control using the Locus of Control of Behavior scale developed by Craig et al. [45].

As seen in Table 2, internal consistency/scale reliability (Cronbach's $\alpha$ ) of the control instruments was reported in 6 articles [19, 21, 23, 26-28]. One study's primary aim was to assess the applicability of the control belief scale for use among persons with dementia [27], while no other studies reported or did any validation of the control belief scales for the included study population. However, no studies reported methodological difficulties with the use of the control belief instruments.

\section{Findings Regarding Control Beliefs}

Five studies examined control beliefs using cross-sectional data. Clare et al. [30] examined the experience of discontinuity in the subjective experience of one self and found that this was associated with lower scores on selfefficacy. Fankhauser et al. [25] found that motivational processes (self-efficacy and activity, motivation, and decision regulation) were associated with depression and furthermore that motivational processes, not degree of social support, predicted depression in a regression analysis. In the study by Lamont et al. [28], high self-efficacy was found to be associated with increases on 3 different living-well scales. However, the effect sizes were reduced when accounting for shared variance with optimism and self-esteem, considered by the authors to be 2 related concepts. Burgener and Berger [21] examined differences in experiences of stigma among participants with $\mathrm{AD}$ and PD. They found that personal control was lower among those with $\mathrm{AD}$ and only associated with stigma among those with dementia due to PD. Finally, Halse et al. [27] found more external locus of control to be associated with more depressive symptoms, but no association between locus of control and cognitive function.

Two descriptive longitudinal studies examined personal control as one of several quality of life variables for participants with dementia. Burgener and Twigg [19] found improvements in personal control over an 18-month period; however, the main hypothesis that such a change could be predicted by caregiver factors was not supported. Burgener et al. [26] examined effects of perceived stigma on quality of life variables and found that personal control was associated with both the social isolation and internalized shame stigma subscales. This was more prominent among participants living in urban areas in the USA and those of African American decent.

The 11 intervention studies reported overall positive effects of the various interventions; however, only 5 found these effects to be potentially associated with changes in control beliefs. Examining the efficacy of an early stage memory loss support group, Logsdon et al. [24] found that the intervention was associated with increased quality of life and that this increase was associated with improved self-efficacy. Quinn et al. [15] found that self-efficacy effect sizes increased in the group receiving a selfmanagement intervention compared to that in a group receiving treatment as usual. This increase persisted 6 months post-intervention, along with improved effect size increases in depression and well-being scores. Statistical analysis was not performed due to small sample size. Hindle et al. [17] found that goal-oriented cognitive rehabilitation was superior regarding self-efficacy at 2 months to both relaxation therapy and treatment as usual, but the effect was not sustained at the 6-month followup. Two small pilot studies also reported on improved self-efficacy after interventions $[22,32]$. In their process of translating and validating a cognitive stimulation therapy manual using 13 participants with dementia, Werheid et al. [32] found that self-efficacy increased from pretest to posttest. Schmitter-Edgecombe et al. [22] found that their 5 participants with dementia showed an increased self-efficacy regarding beliefs about obtaining support from family or friends, one of 3 subscales on the Coping Self-Efficacy Scale.

Finally, 6 studies reported effective interventions, but found no changes in control beliefs. Clare et al. [18] found that goal-oriented cognitive rehabilitation was effective with regard to improved everyday functioning; however, self-efficacy did not change. In a large study evaluating effect of an exercise intervention of physical function, activity, well-being, and exercise self-efficacy, Regan et al. [29] reported increases on all outcomes except self-efficacy. Stockwell-Smith et al. [16] examined effectiveness of a psychosocial intervention for care recipients and carer dyads using both quantitative and qualitative methods. Statistical differences on self-efficacy were not found; however, qualitative reports postintervention indicated increased self-efficacy regarding identifying and accessing community support. Roberts and Silverio [23] examined a 4-session educational and support program. Although the 37 participants with dementia increased their use of several measured coping and health behaviors, no statistical changes were found regarding coping self-effi- 
cacy or psychosocial adjustment to the illness. In a small study including 19 participants with dementia, Leroi et al. [31] examined effectiveness of a sensory intervention to improve quality of life for participants with hearing and/ or vision impairment. Mean increases in quality of life were reported as clinically significant, but only slight changes were found regarding self-efficacy. Finally, Fitzsimmons and Buettner [20] concluded that their group interventions target health promotion as a success, but mean self-efficacy scores remained stable.

\section{Discussion}

To the best of our knowledge, this is the first systematic review conducted of scientific studies investigating constructs of control beliefs among people with dementia. We found 18 studies that met our inclusion criteria, examining a total of 3 different constructs using 9 different control belief scales. The studies had a wide variety of research aims and designs, with good methodological quality. However, 7 studies were pilots, and as many as 10 studies included $<50$ participants with dementia. Lowpowered studies reduce the possibility of detecting effects, increase possibility of false positives, or may inflate effects sizes of valid effects.

Most of the included studies examined control beliefs in relation to an intervention. Knowledge about perceived control is valuable when designing and implementing psychosocial interventions to support and enhance coping with a dementia disorder. Regardless of the idiosyncratic ways dementia can evolve, there is inevitably a fall in functioning in daily activities, in social activities, and in autonomy. A common coping mechanism is withdrawal from that which has become difficult, leading to reduced social network, increased isolation, and increased feelings of helplessness. Some become overwhelmed and experience symptoms of anxiety and depression [46]. Intervention programs should preferably be offered before this happens.

The interventions reported in this review were diverse, aiming to examine feasibility of cognitive rehabilitation, effectiveness of physical exercise, or effectiveness of addressing hearing and vision difficulties $[17,18,22,29,31]$. Other interventions aimed to improve a variety of quality of life variables $[15,20,23,24,32]$ or to increase the use of support services [16]. Two studies had control beliefs as a primary outcome $[15,16]$. Both considered their intervention effective, and one found indication of increased self-efficacy [15].
Five studies had follow-up measures after 6 or more months from baseline. One study reported an increase in personal control over an 18-month period [19], while the other 4 with a timespan of 6 months or more did not find control belief changes [16-18, 26]. However, most studies had a shorter time frame with measures done at baseline and again typically after 2 or 3 months. Dementia progresses differently for all individuals, but in the mild stages of the disease, it can be assumed that the changes are slow and minor. More longitudinal data on the associations between cognitive status and control beliefs are thus needed to examine whether cognitive decline affects a person's perception of control. The included studies could not answer this question because of too short follow-up time and being low-powered.

By observing baseline data, it appears that level of perceived control among people with dementia is comparable to other populations without dementia. The GSES was used in 7 studies, with mean baseline scores ranging from 27.2 to $33.2[15,17,18,20,28,30,32]$. Though not comparable in age, a similar GSES mean of 29.46 (SD 5.33) was reported in a large study with 19,120 participants from 25 countries [47]. Furthermore, the descriptive longitudinal studies measuring personal control with the Mastery scale found mean baseline scores ranging from 23.5 to 25.5. Similar means have been reported among middle-aged adults [48] and older adults without dementia [49]. Although caution is needed in interpreting the results of the included studies due to small sample sizes, it indicates that self-efficacy and personal mastery levels among people with dementia resonate other populations. This is encouraging, from both methodological and coping perspectives.

Studies reporting cross-sectional results found several important associations of control beliefs in people with dementia that are useful for our understanding of coping with the diseases. Two studies examining self-efficacy found that a higher level was associated with less depression and better quality of life $[25,28]$, resonating findings among older people with depression $[8,50]$. Compared to people with $\mathrm{PD}$, people with $\mathrm{AD}$ reported less personal control and scored higher on the internalized shame subscale of a stigma measure [19]. Finally, low self-efficacy was associated with experiencing a discontinuity in their sense of self because of the dementia disease [30]. This feeling of discontinuity was associated with several negative measures, such as higher scores on loneliness and depression and lower scores on quality of life.

The results found in this review support conclusions made by others, for example, that persons with demen- 
tia are prone to thoughts of helplessness, loss of identity, and embarrassment, particularly in the mild stages of the disease process $[46,51]$. People with dementia may also be prone to lowered expectations and prejudice by those in their surroundings, and so-called dementia-ism can be a source of stigma and negative selfstereotypes [52]. Addressing low control expectations has been shown to positively affect memory training among older adults with cognitive deficits [53, 54]. Health-care personnel and informal caregivers assisting people with dementia should focus on control beliefs to enhance coping. Supporting people with dementia to reach own goals by focusing on increasing their perception of control could lead to empowering effects and may thereby reduce some of the negative psychological effects of the disease.

Apart from the study by Halse et al. [27] that validated the Locus of Control of Behavior Scale for people with dementia, none of the studies reported having validated the control belief questionnaire for the current population. Still, the studies did not report difficulties with the use of such questionnaires. Depending on the degree of cognitive deficit, people with dementia may be expected to struggle with questions that require judgments on a Likert-type scale, which is commonly used in such questionnaires. One could speculate that they would answer arbitrarily if they did not understand the questions or how to respond. This should be detectable in an internal reliability analysis, and 7 studies reported a Cronbach's alpha score ranging from 0.69 to 0.90 . This indicates that reliable data regarding control beliefs using quantitative measures can be acquired in this manner, which is supported by the study of Halse et al. [27]. Therefore, we suggest that persons with dementia should be included in this type of research as their voices are important and informative.

Notably, the 18 studies tended to include participants with mild to moderate dementia, and most of those included had either $\mathrm{AD}, \mathrm{VD}$, or a mix of these diseases. Although there is an overall lack of knowledge regarding control beliefs among persons with dementia, studies should also include participants in the severe stages of the disease and with other dementia diagnoses. Furthermore, studies focusing specifically on subgroups with comorbidities such as depression or anxiety would likely give further knowledge on who and how a person with dementia could benefit from a focus on control beliefs to increase coping effectiveness.

This review applied a broad search strategy regarding terms to cover both dementia and control beliefs, and thereby, it should capture most of what has been published in English and in peer-reviewed journals. Furthermore, we applied a strict definition of dementia, meaning that studies mixing our target group with people with mild cognitive impairment were excluded. This was done in order to promote the generalizability of our findings, a necessity also advocated by others [55]. However, particularly due to the exclusion of non-English articles, there may exist additional research on the topic that is missing in this review.

\section{Conclusion and Future Directions}

Understanding how experiences of control influences coping can make it easier for informal caregivers and health-care personnel to give effective support to the person with dementia, allowing them to live independently longer and thereby prevent premature burden on society. This systematic review revealed that too few and small studies exist to conclude on the relations between perceived control and dementia; thus, there is a need for more robust studies. However, our findings support that quantitative research on control beliefs among people with dementia is feasible, and people with dementia are recommended to be included in this type of research. The rising interest in this field of knowledge is encouraging, as it may enlighten best practice and help in the development of effective interventions so that people with dementia can cope and live well with their disease.

\section{Acknowledgment}

We would like to acknowledge the staff at the library at the Norwegian National Advisory Unit on Ageing and Health, particularly Katarina Einarsen Enne, for invaluable assistance in performing the systematic search for this review.

\section{Statement of Ethics}

The study is exempt from Ethical Committee approval as it is a review based on already published research data.

\section{Conflict of Interest Statement}

The authors have no conflicts of interest to declare. 


\section{Funding Sources}

This research was internally founded by the Norwegian National Advisory Unit on Ageing and Health, Vestfold Hospital Trust, Norway.

\section{Appendix 1}

Search words for dementia in different databases

\section{Author Contributions}

I.H., K.E., G.H.B., G.S., and M.L.B. contributed to the design and/or analysis and/or interpretation of data and have contributed in the drafting, revising, and final version of the manuscript. They all agree to be held accountable for the content of the manuscript and have signed an Author Submission Statement declaring this.

\begin{tabular}{|c|c|}
\hline Database & Dementia terms \\
\hline EMBASE & $\begin{array}{l}\text { Dementia/OR Alzheimer disease/OR parkinsonism/OR (lewy adj1 bod*).ab,kw,ti. OR (Parkinson* adj1 dementia).ab,kw,ti. OR } \\
\text { (dementia* or alzheimer*).ab,kw,ti. OR (frontotemp* adj1 dementia).ab,kw,ti. OR (vascul*adj1 dementia).ab,kw,ti. }\end{array}$ \\
\hline MEDLINE & $\begin{array}{l}\text { Dementia/or alzheimer disease/or dementia, vascular/or frontotemporal lobar degeneration/or lewy body disease/OR (dementia* or } \\
\text { alzheimer* or (lewy adj } 1 \text { bod*) or (parkinson* adj1 dementia*)).ab,kf,kw,ti. OR parkinsonism.mp. [mp = title, abstract, original title, } \\
\text { name of substance word, subject heading word, floating sub-heading word, keyword heading word, organism supplementary concept } \\
\text { word, protocol supplementary concept word, rare disease supplementary concept word, unique identifier, synonyms] }\end{array}$ \\
\hline CINAHL & $\begin{array}{l}\text { TI dement* OR AB dement* OR SU dement* OR TI alzheimer* OR AB alzheimer* OR SU alzheimer* OR (MH “Lewy Body Disease") } \\
\text { OR TI parkinson* N1 dement* OR AB parkinson* N1 dement* OR SU parkinson* N1 dement* OR (MH "Dementia+") OR (MH } \\
\text { "Alzheimer’s Disease") }\end{array}$ \\
\hline PSYCHINFO & $\begin{array}{l}\text { Dementia/or dementia with lewy bodies/or presenile dementia/or semantic dementia/or senile dementia/or vascular dementia/OR } \\
\text { alzheimer's disease/OR “alzheimer*”.ab,mh,sh,ti. OR “dement*”.ab,mh,sh,ti. OR (lewy adj1 bod*).ab,mh,sh,ti. OR (parkinson* adj1 } \\
\text { dement*).ab,mh,sh,ti. }\end{array}$ \\
\hline AGELINE & 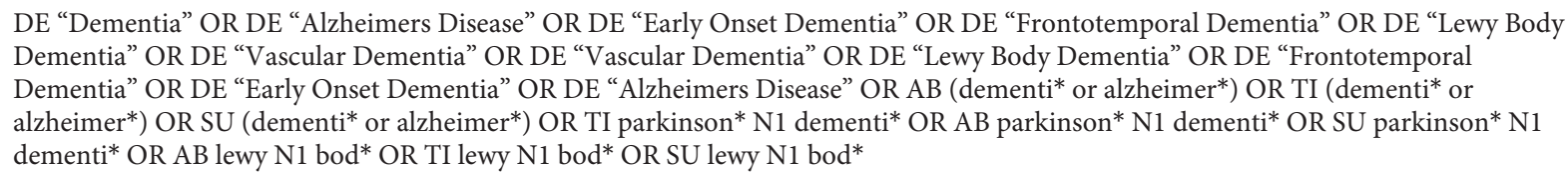 \\
\hline COCHRANE & $\begin{array}{l}\text { MeSH descriptor: [Dementia] explode ORMeSH descriptor: [Alzheimer Disease] explode OR (dementi* OR alzheimer* OR lewy OR } \\
\text { parkinsonism):ti,ab,kw }\end{array}$ \\
\hline
\end{tabular}




\section{Appendix 2}

Search words for control and coping in different databases

\begin{tabular}{ll}
\hline Database & Coping terms \\
\hline EMBASE & Coping behavior/OR (coping adj1 (strateg* or style* or mechanism* or behavio* or way*)).ab,ti,kw. OR "locus of control assessment”/or \\
& internal-external control scale/or "multidimensional health locus of control scale"/OR "locus of control”/OR "locus of control”.ab,kw,ti. \\
& OR control/OR *self concept/OR (control adj1 (personal or subjectiv* or belief* or perceived or orientation or sense or expectancy)). \\
& ab,kw,ti. OR self-efficacy.ab,kw,ti. OR "sense of coherence scale"/OR "sense of coherence"/OR "sense of coherence".ab,kw,ti. OR learned \\
& helplessness.ab,kw,ti. OR learned helplessness/OR personal causation.ab,kw,ti. OR situation appraisal.ab,kw,ti. OR perceived competence. \\
& ab,kw,ti. OR efficacy expectancies.ab,kw,ti. OR "agency belief*”.ab,kw,ti. OR ways of coping.ab,kw,ti. OR mastery.ab,kw,ti.
\end{tabular}

MEDLINE (Coping adj1 (strateg* or style* or mechanism* or behavio* or way*)).ab,ti,kw,kf. OR Internal-External Control/OR "locus of control”. ab,kw,ti,kf. OR (control adj1 (personal or subjectiv* or belief* or perceived or orientation or sense or expectancy)).ab,kw,ti. OR selfefficacy.ab,kw,ti,kf. OR "sense of coherence".ab,kw,ti,kf. OR learned helplessness.ab,kw,ti,kf. OR personal causation.ab,kw,ti,kf. OR situation appraisal.ab,kw,ti,kf. OR perceived competence.ab,kw,ti,kf. OR efficacy expectancies.ab,kw,ti,kf. OR “agency belief*”.ab,kw,ti,kf. OR ways of coping.ab,kw,ti,kf. OR mastery.ab,kw,ti,kf. OR Internal-External Control/OR Helplessness, Learned/OR Self Efficacy/OR "Sense of Coherence"/OR Adaptation, Psychological/

CINAHL (MH “Coping+”) OR TI ((coping w1 (behavio** OR style* OR strateg* OR mechanism* or way*))) OR AB ((coping w1 (behavio* OR style* OR strateg* OR mechanism* or way*))) OR SU ((coping w1 (behavio* OR style* OR strateg* OR mechanism* or way*))) OR (MH "Locus of Control") OR (MH "Self Regulation") OR TI ((control N1 (orientation OR sense OR expectancy OR belief* OR personal OR perceived or expectancy))) OR AB ((control N1 (orientation OR sense OR expectancy OR belief* OR personal OR perceived or expectancy))) OR SU ((control N1 (orientation OR sense OR expectancy OR belief* OR personal OR perceived or expectancy))) OR (MH "Helplessness, Learned") OR sense of coherence OR "mastery" OR TI (efficacy expectancie* or agency belief* or situation appraisal* or perceived competence* or mastery or self-efficacy) OR AB (efficacy expectancie* or agency belief* or situation appraisal* or perceived competence* or mastery or self-efficacy) OR SU (efficacy expectancie* or agency belief* or situation appraisal* or perceived competence* or mastery or self-efficacy) OR TI locus of control OR AB locus of control OR SU locus of control

PSYCHINFO (Coping adj1 (strateg* or style* or mechanism* or behavio* or way*)).ab,ti,sh. OR "internal external locus of control"/OR "locus of control".ab,ti,sh. OR (control adj1 (personal or subjectiv* or belief* or perceived or orientation or sense or expectancy)).ab,sh,ti. OR selfefficacy.ab,sh,ti. OR "sense of coherence".ab,ti,sh. OR learned helplessness.ab,ti,sh. OR personal causation.ab,sh,ti. OR situation appraisal. ab,sh,ti. OR perceived competence.ab,ti,sh. OR efficacy expectancies.ab,ti,sh. OR “agency belief*”.ab,ti,sh. OR ways of coping.ab,ti,sh. OR mastery.ab,ti,sh. AND Helplessness, Learned/OR Self Efficacy/OR "sense of coherence"/OR coping behavior/OR *self-control/OR helplessness/or learned helplessness/OR exp Self-Perception/

AGELINE DE “Coping Behavior" OR TI ((coping w1 (behavio* OR style* OR strateg* OR mechanism* or way*))) OR AB ((coping w1 (behavio* OR style* OR strateg* OR mechanism* or way*))) OR SU ((coping w1 (behavio* OR style* OR strateg* OR mechanism* or way*))) OR TI ((control N1 (orientation OR sense OR expectancy OR belief* OR personal OR perceived or expectancy))) OR AB ((control N1 (orientation OR sense OR expectancy OR belief* OR personal OR perceived or expectancy))) OR SU ((control N1 (orientation OR sense OR expectancy OR belief* OR personal OR perceived or expectancy))) OR DE "Learned Helplessness" or DE "Locus of Control" or DE "Self Efficacy" OR TI (efficacy expectancie* or agency belief* or situation appraisal* or perceived competence* or mastery or self-efficacy or sense of coherence) OR AB (efficacy expectancie* or agency belief* or situation appraisal* or perceived competence* or mastery or self-efficacy or sense of coherence) OR SU (efficacy expectancie* or agency belief* or situation appraisal* or perceived competence* or mastery or self-efficacy or sense of coherence) OR TI locus of control OR AB locus of control OR SU locus of control

COCHRANE MeSH descriptor: [Adaptation, Psychological] explode OR MeSH descriptor: [Self Concept] explode (coping):ti,ab,kw OR (locus of control):ti,ab,kw OR ("control orientation" or "sense of control" or "control expectancy" or "control belief*" or "personal control" or "perceived control" or "perception of control" or "self-efficacy" or "sense of coherence" or "personal causation" or "learned helplessness" or "situation appraisal" or "perceived competence" or "efficacy expectanci*” or "agency belief*" or "way* of coping" or mastery):ti,ab,kw

\section{References}

Control Beliefs among People with Dementia
1 Livingston G, Sommerlad A, Orgeta V, Costafreda SG, Huntley J, Ames D, et al. Dementia prevention, intervention, and care. Lancet. 2017 Dec 16;390(10113):2673-734.

2 Testad I, Clare L, Anstey K, Selbæk G, Bjørkløf GH, Henderson C, et al. Self-management and HeAlth Promotion in Early-stage dementia with e-learning for carers (SHAPE): study protocol for a multi-centre randomised controlled trial. BMC Public Health. 2020 Oct 9; 20(1):1508.
3 Wallston KA. Control beliefs: health perspectives. In: Wrigth JD, editor. International Encyclopedia of the Social \& Behavioral Sciences. Elsevier Ltd; 2015. p. 819-21.

4 Robinson SA, Lachman ME. Perceived control and aging: a mini-review and directions for future research. Gerontology. 2017;63(5): 435-42.

5 Skinner EA. A guide to constructs of control. J Pers Soc Psychol. 1996;71(3):549-70. 
6 Judge TA, Bono JE. A rose by any other name: are self-esteem, generalized self-efficacy, neuroticism, and locus of control indicators of a common construct? Personality psychology in the workplace. Decade of behavior. Washington, DC: American Psychological Association; 2001. p. 93-118.

7 Lachman ME, Neupert SD, Agrigoroaei S. Chapter 11: the relevance of control beliefs for health and aging. In: Schaie KW, Willis SL, editors. Handbook of the psychology of aging. 7th ed. San Diego: Academic Press; 2011. p. 175-90.

8 Mallers M, Claver M, Lares L. Perceived control in the lives of older adults: the influence of Langer and Rodin's work on gerontological theory, policy, and practice. Gerontologist. 2014 Feb;54(1):67-74.

9 Reich JW, Infurna FJ. Perceived control: theory, research, and practice in the first 50 years. New York, NY: Oxford University Press; 2017.

10 Langer EJ, Rodin J. The effects of choice and enhanced personal responsibility for the aged: a field experiment in an institutional setting. J Pers Soc Psychol. 1976;34(2):191-8.

11 Rodin J, Langer EJ. Long-term effects of a control-relevant intervention with the institutionalized aged. J Pers Soc Psychol. 1977 Dec;35:897-902.

12 Neupert SD, Allaire JC. I think I can, I think I can: examining the within-person coupling of control beliefs and cognition in older adults. Psychol Aging. 2012;27(3):742-9.

13 Bandura A. Self-efficacy: toward a unifying theory of behavioral change. Psychol Rev. 1977 Mar;84(2):191-215.

14 Hawker S, Payne S, Kerr C, Hardey M, Powell J. Appraising the evidence: reviewing disparate data systematically. Qual Health Res. 2002 Nov; 12(9): 1284-99.

15 Quinn C, Toms G, Jones C, Brand A, Edwards RT, Sanders F, et al. A pilot randomized controlled trial of a self-management group intervention for people with early-stage dementia (the SMART study). Int Psychogeriatr. 2016 May;28(5):787-800.

16 Stockwell-Smith G, Moyle W, Kellett U. The impact of early psychosocial intervention on self-efficacy of care recipient/carer dyads living with early-stage dementia-A mixed-methods study. J Adv Nurs. 2018;74(9):2167-80.

17 Hindle JV, Watermeyer TJ, Roberts J, Brand A, Hoare Z, Martyr A, et al. Goal-orientated cognitive rehabilitation for dementias associated with Parkinson's disease-A pilot randomised controlled trial. Int J Geriatr Psychiatry. 2018;33(5):718.

18 Clare L, Kudlicka A, Oyebode JR, Jones RW, Bayer A, Leroi I, et al. Individual goal-oriented cognitive rehabilitation to improve everyday functioning for people with early-stage dementia: a multicentre randomised controlled trial (the GREAT trial). Int J Geriatr Psychiatry. 2019;34:709-21.
19 Burgener S, Twigg P. Relationships among caregiver factors and quality of life in care recipients with irreversible dementia. Alzheim er Dis Assoc Disord. 2002;16(2):88-102.

20 Fitzsimmons S, Buettner LL. Health promotion for the mind, body, and spirit: a college course for older adults with dementia. Am J Alzheimers Dis Other Demen. 2003;18(5): 282-90.

21 Burgener SC, Berger B. Measuring perceived stigma in persons with progressive neurological disease: Alzheimer's dementia and Parkinson's Disease. Dementia Int J Soc Res Pract. 2008 Feb;7(1):31-53.

22 Schmitter-Edgecombe M, Howard JT, Pavawalla SP, Howell L, Rueda A. Multidyad memory notebook intervention for very mild dementia: a pilot study. Am J Alzheimers Dis Other Demen. 2008;23(5):477-87.

23 Roberts JS, Silverio E. Evaluation of an education and support program for early-stage $\mathrm{Al}$ zheimer's disease. J Appl Gerontol. 2009 Aug; 28(4):419-35.

24 Logsdon RG, Pike KC, McCurry SM, Hunter P, Maher J, Snyder L, et al. Early-stage memory loss support groups: outcomes from a randomized controlled clinical trial. J Gerontol B Psychol Sci Soc Sci. 2010;65(6):691-7.

25 Fankhauser S, Drobetz R, Mortby M, Maercker A, Forstmeier S. Depressive symptoms in later life: differential impact of social support and motivational processes on depression in individuals with and without cognitive impairment. Eur J Ageing. 2014 Dec;11(4):32132.

26 Burgener SC, Buckwalter K, Perkhounkova Y, Liu MF. The effects of perceived stigma on quality of life outcomes in persons with earlystage dementia: longitudinal findings: part 2. Dementia. 2015 Sep;14(5):609-32.

27 Halse I, Bjørkløf GH, Engedal K, Rokstad AMM, Persson K, Eldholm RS, et al. Applicability of the locus of control of behaviour scale for people with dementia. Aging Ment Health. 2020 Dec;24(12):2111-6.

28 Lamont RA, Nelis SM, Quinn C, Martyr A, Rippon I, Kopelman MD, et al. Psychological predictors of 'living well' with dementia: findings from the IDEAL study. Aging Ment Health. 2020 Jun;24(6):956-64.

29 Regan K, White F, Harvey D, Middleton LE. Effects of an exercise and mental activity program for people with dementia and their care partners. J Aging Phys Act. 2019;27(2):27683.

30 Clare L, Martyr A, Morris RG, Tippett LJ. Discontinuity in the subjective experience of self among people with mild-to-moderate dementia is associated with poorer psychological health: findings from the IDEAL Cohort. J Alzheimers Dis. 2020;77(1):127-38.

31 Leroi I, Simkin Z, Hooper E, Wolski L, Abrams H, Armitage CJ, et al. Impact of an intervention to support hearing and vision in dementia: the SENSE-Cog field trial. Int J Geriatr Psychiatry. 2020;35(4):348-57.
32 Werheid K, Schaubs B, Aguirre E, Spector A. Cognitive stimulation therapy: model-based cultural adaptation and manual translation of an evidence-based psychosocial group therapy for people with dementia. GeroPsych. 2020.

33 World Health Organization. ICD-10: international statistical classification of diseases and related health problems. Geneva: World Health Organization; 2004.

34 American Psychiatric Association Task Force on D-I, American Psychiatric A. Diagnostic and statistical manual of mental disorders: DSMIV-TR. 4th ed., text revision ed. Washington, DC: American Psychiatric Association; 2000.

35 Morris JC. Clinical dementia rating: a reliable and valid diagnostic and staging measure for dementia of the Alzheimer type. Int Psychogeriatr. 1997;9(Suppl 1):173-8.

36 McKhann G, Drachman D, Folstein M, Katzman R, Price D, Stadlan EM. Clinical diagnosis of Alzheimer's disease: report of the NINCDS-ADRDA Work Group under the auspices of Department of Health and $\mathrm{Hu}$ man Services Task Force on Alzheimer's Disease. Neurology. 1984 Jul;34(7):939-44.

37 Dubois B, Burn D, Goetz C, Aarsland D, Brown RG, Broe GA, et al. Diagnostic procedures for Parkinson's disease dementia: recommendations from the movement disorder society task force. Mov Disord. 2007 Dec;22(16):2314-24.

38 Emre M, Aarsland D, Brown R, Burn DJ, Duyckaerts C, Mizuno Y, et al. Clinical diagnostic criteria for dementia associated with Parkinson's disease. Mov Disord. 2007 Sep 15; 22(12):1689-837.

39 McKeith IG, Dickson DW, Lowe J, Emre M, O'Brien JT, Feldman H, et al. Diagnosis and management of dementia with Lewy bodies: third report of the DLB Consortium. Neurology. 2005 Dec 27;65(12):1863-72.

40 Folstein MF, Folstein SE, McHugh PR. "Minimental state". A practical method for grading the cognitive state of patients for the clinician. J Psychiatr Res. 1975;12(3):189-98.

41 Hughes CP, Berg L, Danziger WL, Coben LA, Martin RL. A new clinical scale for the staging of dementia. Br J Psychiatry. 1982;140(6): 566-72.

42 Nasreddine ZS, Phillips NA, Bédirian V, Charbonneau S, Whitehead V, Collin I, et al. The Montreal Cognitive Assessment, MoCA: a brief screening tool for mild cognitive impairment. J Am Geriatr Soc. 2005;53(4):695-9.

43 Schwarzer R, Jerusalem M. Measures in health psychology: a user's Portfolio. Causal control beliefs. 1995. p. 35-7.

44 Pearlin LI, Schooler C. The structure of coping. J Health Soc Behav. 1978;19(1):2-21.

45 Craig AR, Franklin JA, Andrews G. A scale to measure locus of control of behaviour. Br J Med Psychol. 1984;57(Pt 2):173-80.

46 Bjørkløf GH, Helvik AS, Ibsen TL, Telenius EW, Grov EK, Eriksen S. Balancing the struggle to live with dementia: a systematic metasynthesis of coping. BMC Geriatr. 2019 Oct 30;19(1):295. 
47 Scholz U, Doña BG, Sud S, Schwarzer R. Is general self-efficacy a universal construct? Psychometric findings from 25 countries. Eur J Psychol Assess. 2002;18(3):242-51.

48 Bergland A, Nicolaisen M, Thorsen K. Predictors of subjective age in people aged 40-79 years: a five-year follow-up study. The impact of mastery, mental and physical health. Aging Ment Health. 2014 Jul;18(5):653-61.

49 Jang Y, Haley WE, Small BJ, Mortimer JA. The role of mastery and social resources in the associations between disability and depression in later life. Gerontologist. 2002 Dec; 42(6):807-13.

50 Bjørkløf GH, Engedal K, Selbæk G, Kouwenhoven SE, Helvik AS. Coping and depression in old age: a literature review. Dement Geriatr Cogn Disord. 2013;35(3/4):121-54.

51 Choi J, Twamley EW. Cognitive rehabilitation therapies for Alzheimer's disease: a review of methods to improve treatment engagement and self-efficacy. Neuropsychol Rev. 2013;23(1):48-62
52 Brooker D. What is person-centred care in dementia? Rev Clin Gerontol. 2003;13(3): 215-22.

53 Lachman ME, Weaver SL, Bandura M, Elliott E, Lewkowicz CJ. Improving memory and control beliefs through cognitive restructuring and self-generated strategies. J Gerontol. 1992;47(5):P293-9.

54 Parisi JM, Gross AL, Marsiske M, Willis SL, Rebok GW. Control beliefs and cognition over a 10 -year period: findings from the ACTIVE trial. Psychol Aging. 2017;32(1):69-75.

55 Spreadbury JH, Kipps CM. Measuring younger onset dementia: a comprehensive literature search of the quantitative psychosocial research. Dementia. 2019 Jan;18(1):135-56.

56 Chen G, Gully SM, Eden D. Validation of a new general self-efficacy scale. Organ Res Methods. 2001;4(1):62-83.
57 Seeman T, McAvay G, Merrill S, Albert M, Rodin J. Self-efficacy beliefs and change in cognitive performance: MacArthur studies on Successful Aging. Psychol Aging. 1996; 11(3):538-51.

58 Resnick B, Jenkins LS. Testing the reliability and validity of the self-efficacy for exercise scale. Nurs Res. 2000;49(3):154-9.

59 Merluzzi TV, Martinez Sanchez MA. Assessment of self-efficacy and coping with cancer: development and validation of the Cancer Behavior Inventory. Health Psychol. 1997;16(2): $163-70$.

60 Chesney MA, Neilands TB, Chambers DB, Taylor JM, Folkman S. A validity and reliability study of the coping self-efficacy scale. Br J Health Psychol. 2006;11(Pt 3):421-37.

61 Fortinsky RH, Kercher K, Burant CJ. Measurement and correlates of family caregiver self-efficacy for managing dementia. Aging Ment Health. 2002 May;6(2):153-60. 